\title{
Correction: British Thoracic Society Winter Meeting 2019
}

British Thoracic Society Winter Meeting 2019.Thorax 2019;74(Suppl 2):A1-A249. https:// thorax.bmj.com/content/74/Suppl_2

Since initial publication of these abstracts there are some changes and additions required as follows:

10.1136/thorax-2019-BTSabstracts2019.46

Abstract withdrawn - not presented at the meeting

10.1136/thorax-2019-BTSabstracts2019.213

Abstract withdrawn - not presented at the meeting

10.1136/thorax-2019-BTSabstracts2019.387

Abstract withdrawn — not presented at the meeting

10.1136/thorax-2019-BTSabstracts2019.425

Abstract withdrawn - not presented at the meeting

10.1136/thorax-2019-BTSabstracts2019.433

Abstract withdrawn — not presented at the meeting

10.1136/thorax-2019-BTSabstracts2019.421

The incorrect version of the conclusion was published and the reference was omitted. See updates below:

Over a twelve-month period, one-third of referrals were diagnosed with IPF by the NILDS MDT consensus. One-third of patients with IPF were started on AFM. A disparity in the choice of AFM is evident with the majority of patients receiving Nintedanib for treatment of their IPF.

The majority of patients are above the therapeutic threshold at the time of MDT review. Monitoring FVC at regular follow-up is therefore vital to ensure treatment initiation at earliest opportunity.

\section{Reference:}

1. National Institute for Health and Care Excellence (2013). Idiopathic pulmonary fibrosis in adults: diagnosis and management. (NICE Clinical Guideline 163)

10.1136/thorax-2019-BTSabstracts2019.372

There was an amendment to the Results paragraph. See corrected version below:

Results: A total of 894 patients initiating FF/VI were matched to 3433 patients initiating BDP/ FM. A higher proportion of patients persisted with FF/VI vs BDP/FM over 12 months (KaplanMeier analysis; Figure). The likelihood of discontinuing treatment within 12 months after initiation was 31\% lower for $\mathrm{FF} / \mathrm{VI}$ than $\mathrm{BDP} / \mathrm{FM}$ (index year-adjusted, $\mathrm{HR}=0.69$; $95 \% \mathrm{CI}$ 0.60 to $0.80 ; \mathrm{p}<0.001)$. Mean (SD) PDC was $78.2(25.1)$ for FF/VI and 71.0 (26.0) for BDP/FM ( $<<0.0001)$, with median 89.2 vs 75.9 and significantly higher odds of achieving $\geq 50 \%$ and $\geq 80 \%$ PDC for FF/VI vs BDP/FM (747/893 [83.7\%] vs 2600/3433 [75.7\%]; $\mathrm{OR}=1.50 ; 95 \% \mathrm{CI} 1.23$ to $1.83 ; \mathrm{p}<0.001$ and $526 / 893$ [58.9\%] vs $1571 / 3433$ [45.8\%]; $\mathrm{OR}=1.57 ; 95 \% \mathrm{CI} 1.35$ to $1.83 ; \mathrm{p}<0.001$, respectively; per-protocol analyses). Annualised rescue use was numerically similar for FF/VI (4.6) vs BDP/FM (4.7).

10.1136/thorax-2019-BTSabstracts2019.373

There was an amendment to the Results paragraph. See corrected version below:

Results: A total of 937 patients initiating FF/VI were matched to 3232 patients initiating BUD/ FM. A higher proportion of patients persisted with FF/VI vs BUD/FM over 12 months (KaplanMeier analysis; Figure). The likelihood of discontinuing treatment within 12 months after initiation was 35\% lower for FF/VI than BUD/FM (index year-adjusted, $\mathrm{HR}=0.65$; 95\% CI 0.56 to $0.75 ; \mathrm{p}<0.001)$. Mean (SD) PDC was 77.7 (25.3) for FF/VI and 72.4 (26.1) for BUD/FM ( $\mathrm{p}<0.0001)$, with median 88.2 vs 77.7 and significantly higher odds of achieving $\geq 50 \%$ and $\geq 80 \%$ PDC for FF/VI vs BUD/FM (779/936 [83.2\%] vs 2447/3232 [75.7\%]; 
$\mathrm{OR}=1.35 ; 95 \% \mathrm{CI} 1.09$ to $1.67 ; \mathrm{p}=0.006$ and $544 / 936$ [58.1\%] vs $1562 / 3232$ [48.3\%]; $\mathrm{OR}=1.28 ; 95 \% \mathrm{CI} 1.08$ to $1.52 ; \mathrm{p}=0.004$, respectively; per-protocol analyses). Annualised rescue use was numerically similar for FF/VI (4.7) vs BUD/FM (4.2).

10.1136/thorax-2019-BTSabstracts2019.186

The author list has been changed to include LA Boast:

LA Boast, CA Peal, AD Moriarty, J Wyatt, AW Molyneux, DP Smith. Sherwood Forest Hospitals, Sutton in Ashfield, UK

10.1136/thorax-2019-BTSabstracts2019.208

The author list has been changed to include PS McNamara:

PB Bhatia, PS McNamara. University of Liverpool - School of Medicine, Liverpool, UK

10.1136/thorax-2019-BTSabstracts2019.97

The author list has been changed to include L Organ:

L Organ, J Porte, A John, RG Jenkins. The University of Nottingham, Nottingham, UK

(C) Author(s) (or their employer(s)) 2020. No commercial re-use. See rights and permissions. Published by BMJ.

Thorax 2020;75:e2. doi:10.1136/thorax-2019-BTSabstracts-corr

D Check for updates 